\title{
MAMONA: DETERMINAÇÃO QUANTITATIVA DO TEOR DE ÓLEO (1)
}

\author{
MfRIAM BOTTIGLIA TAMBASCIA $\left({ }^{2}\right)$ e JOÃO PAULO FEIJÃO TEIXEIRA $(2,3)$
}

\begin{abstract}
RESUMO
Foi desenvolvida uma metodologia para quantificar o teor de óleo em sementes de mamona, a partir da determinação do índice de refração de soluçōes etanólicas de diferentes concentraçōes a diferentes temperaturas. Os resultados mostraram um comportamento linear entre indice de refração e concentraçāo de óleo para cada temperatura, com um excelente coeficiente de correlação, permitindo, assim, a quantificação do teor de óleo de mamona por metodologia bastante rápida e precisa.
\end{abstract}

Termos de indexação: mamona, óleo, índice de refraçâo.

\section{INTRODUÇÃO}

As análises em sementes de mamona têm mostrado teor de óleo ao redor de $50 \%$ na matéria seca (TAMBASCIA et alii, 1984). Esse alto valor dificulta a determinação através do uso de extratores Soxhlet, devido a perdas durante

(1) Recebido para publicação em 27 de novembro de 1984.

(2) Seçäo de Fitoquímica, Instituto Agronómico (IAC), Caixa Postal 28, 13001 Campinas (SP).

(3) Com bolsa de suplementaçâo do CNPq. 
moagem e manuseio das amostras, além do alto custo individual de cada análise quando se utiliza o solvente hexano. Visando definir técnica alternativa, desenvolveu-se metodologia com igual eficiência, maior rapidez e economia (TAMBASCIA et alii, 1984), onde as sementes são desintegradas em presença de álcool etílico hidratado, evitando perdas de óleo e procedendo-se à extração a frio. $O$ óleo de mamona, cujo principal ácido graxo é o ácido ricinoléico, apresenta alta solubilidade em etanol (BOLLIGER, 1938). Após essa extração, a avaliação do óleo extraido poderia ser efetuada pela pesagem do resíduo após evaporação do álcool, processo dificil e que ocasiona alteraçōes no óleo, ou algum método que dosasse a concentração nas soluções alcoólicas obtidas. Para tanto, aventou-se a hipótese da utilização do índice de refração das soluções para avaliar o teor de óleo, sabendo-se que esse índice é característico de cada óleo, sendo utilizado na identificação desses compostos e como indicador de pureza, além de apresentar relação linear com o indice de iodo de óleos e gorduras (TRIEBOLD \& AURAND, 1963). Embora não se encontrasse indicaçāo para o pretendido na literatura, havia a conhecida aplicação para quantificar açúcares em soluções aquosas (TRIEBOLD \& AURAND, 1963) e caldo de cana (ZULLO \& RAMOS, 1984), além de resultados preliminares satisfatórios.

O objetivo deste trabalho foi o desenvolvimento de metodologia para determinação do teor de óleo de mamona em soluções alcoólicas por refratometria.

\section{MATERIAL E MÉTODOS}

O óleo utilizado neste estudo foi extraido através de prensagem das sementes de mamona provenientes de campos experimentais da Seção de Oleaginosas do Instituto Agronômico.

Os ensaios foram realizados, misturando-se em diferentes concentrações, em massa, etanol hidratado $96^{\circ} \mathrm{GL}$ e óleo de mamona. Posteriormente, efetuou-se a leitura do indice de refração das misturas mantidas a temperatura constante e conhecida. A avaliação foi efetuada utilizando refratômetro ABBE-3L, BAUSCH \& LOMB. Foram realizadas determinações em sementes de mamona 'Guarani', pelo método refratométrico proposto, após extração com etanol hidratado a frio (TAMBASCIA et alii, 1984) e com hexano, a quente, através de extratores Soxhlet (TRIEBOLD \& AURAND, 1963), para se ter informações sobre a aplicabilidade da nova metodologia.

\section{RESULTADOS E DISCUSSÃO}

Soluções alcoólicas contendo 0 a $10 \%$ de óleo de mamona, em peso, tiveram o índice de refração determinado a diferentes temperaturas, 20 a $25^{\circ} \mathrm{C}$. Os resultados obtidos (Quadro 1) confirmaram a expectativa, devido à existência de 
uma resposta linear entre o indice de refração e a concentração de óleo na mistu$\mathrm{ra}$, desde que a temperatura seja controlada. As equações de regressão linear obtidas a partir desses dados para cada temperatura mostraram alto coeficiente de correlação entre esses parâmetros $\left(r^{2}=0,99\right)$.

QUADRO 1. Variação do índice de refração em função da concentração de óleo e da temperatura em soluçōes alcoólicas

\begin{tabular}{ccccccc}
\hline \multirow{7}{*}{ Óleo } & \multicolumn{6}{c}{ Temperatura $\left({ }^{\circ} \mathrm{C}\right)$} \\
\cline { 2 - 7 } & 20 & 21 & 22 & 23 & 24 & 25 \\
\hline$\%$ & & & & & & \\
0 & 1,3634 & 1,3629 & 1,3624 & 1,3619 & 1,3614 & 1,3609 \\
1 & 1,3644 & 1,3638 & 1,3634 & 1,3629 & 1,3624 & 1,3619 \\
2 & 1,3654 & 1,3649 & 1,3644 & 1,3639 & 1,3634 & 1,3629 \\
3 & 1,3665 & 1,3659 & 1,3655 & 1,3650 & 1,3645 & 1,3640 \\
4 & 1,3675 & 1,3670 & 1,3665 & 1,3660 & 1,3655 & 1,3650 \\
5 & 1,3686 & 1,3680 & 1,3676 & 1,3671 & 1,3666 & 1,3661 \\
6 & 1,3696 & 1,3691 & 1,3686 & 1,3681 & 1,3676 & 1,3671 \\
7 & 1,3706 & 1,3701 & 1,3696 & 1,3691 & 1,3686 & 1,3681 \\
8 & 1,3717 & 1,3712 & 1,3707 & 1,3702 & 1,3697 & 1,3692 \\
9 & 1,3727 & 1,3723 & 1,3717 & 1,3712 & 1,3707 & 1,3702 \\
10 & 1,3738 & 1,3733 & 1,3728 & 1,3723 & 1,3718 & 1,3713 \\
\hline
\end{tabular}

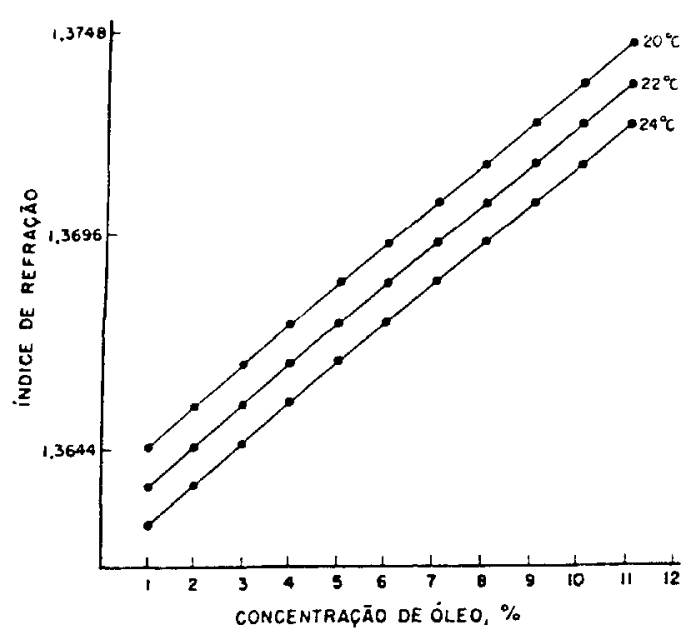

FIGURA 1. Variação do índice de refração em função da concentração de bleo em soluções alcoólicas a diferentes temperaturas. 
Visando a uma simplificação na aplicação desse método, desenvolveu-se a seguinte equação, que leva em conta a variação do índice de refração (IR) em função da concentração de óleo (Co) e da temperatura (T):

$$
\mathrm{IR}=1,37334+1,04178 \times 10^{-3} \mathrm{Co}-4,99286 \times 10^{-4} \mathrm{~T}
$$

e apresenta como coeficiente de determinação um valor alto $\left(r^{2}=0,99\right)$ e para desvio-padrão, $s=0,00019$.

Desse modo, essa equação possibilita o cálculo da concentração de óleo mediante o conhecimento do índice de refração da mistura estudada e temperatura das soluções. Para essa determinação, um cuidado deverá ser tomado, ou seja, o índice de refração do solvente puro em dada temperatura deverá coincidir $( \pm 0,00019)$ com o apresentado no quadro 1 . Esse cuidado se deve à variabilidade existente no índice de refração do álcool etílico hidratado, comercial, devido a diferenças de acordo com sua pureza.

Aplicou-se a técnica para determinação da concentração de óleo em sementes, utilizando inicialmente extração com etanol hidratado (TAMBASCIA et alii, 1984). Os resultados foram considerados satisfatórios quando comparados a resultados obtidos com extratores Soxhlet (Quadro 2).

QUADRO 2. Avaliação do teor de óleo em sementes de mamona cv.Guarani através de dois métodos analíticos

\begin{tabular}{lcc}
\hline & \multicolumn{3}{c}{ Óleo na matéria fresca (\%) } \\
\cline { 2 - 3 } & Soxhlet $\left(^{1}\right)$ & Refratometria $\left(^{2}\right)$ \\
\hline 1 & $\%$ & $\%$ \\
2 & 49,95 & 47,10 \\
3 & 48,64 & 46,95 \\
4 & 49,17 & 45,72 \\
5 & 50,03 & 45,64 \\
6 & 51,36 & 46,08 \\
7 & 49,23 & 45,72 \\
8 & 45,70 & 44,81 \\
9 & 45,89 & 47,02 \\
10 & 45,48 & 47,03 \\
Média & 45,54 & 44,32 \\
\hline
\end{tabular}

( ${ }^{1}$ Extração em Soxhlet, com aquecimento e solvente hexano.

(2) Extração com moagem em presença de etanol, a frio. 
A técnica descrita permite a quantificação do teor de óleo de mamona de forma rápida e eficiente. Dessa maneira, poderá ser aplicada na avaliação de sementes de mamona quanto ao teor de óleo visando à economia de energia e al to rendimento analítico.

A utilização de métodos como o apresentado é de importância no auxílio à seleção de plantas em programas de melhoramento genético, onde grande número de análises é necessário.

\section{SUMMARY}

\section{QUANTITIVE DETERMINATION OF CASTOR OIL}

A methodology was developed to quantify the castor oil seed content, through the determination of refractive index of ethanolic solutions with different oil concentrations and temperatures. The results showed a nearly linear relationship between the refractive index and oil concentration for each temperature. This correlation permits to quantify castor oil content of ethanolic solutions by calculation from the quickly and accurate measurement of refractive index.

Index terms: castor oil, refractive index.

\section{AGRADECIMENTO}

A Regina Prado Zanes, Seção de Fitoquímica, pelo apoio e execução dos trabahos experimentais.

\section{REFERÊNCIAS BIBLIOGRÁFICAS}

BOLLIGER, R. Método rápido para a dosagem do b́leo nas sementes oleaginosas (Tung e Mamona). São Paulo, Secretaria da Agricultura, 1938. (Boletim técnico, 43)

TAMBASCIA, M.B.; TEIXEIRA, J.P.F. \& SAVY FILHO, A. Modificação do método de extração de óleo de mamona, utilizando etanol hidratado como solvente. In: CONGRESSO BRASILEIRO DE ENERGIA, 3., Rio de Janeiro, 1984. Anais. Rio de Janeiro, COPPE/UFRJ, 1984 . v.4, p.1614-1619.

TRIEBOLD, H.O. \& AURAND, L.W. General procedures and methods used in food analysis. In: $-\& 1$. Food composition and analysis. New York, Van Nostrand Reinhold, 1963. cap. 2, p.9-37.

ZULLO,M.A.T. \& RAMOS, M.T.B. Cálculo de resultados em análises tecnológicas de cana-de-açúcar pelo método da prensa. Pesquisa Agropecuária Brasileira, Brasília, 19(4):495-498, 1984. 